\title{
Acercamientos a asociaciones de mujeres campesinas en Colombia y proyecto ético-político del Trabajo social*
}

\author{
[Versión en Español] \\ Approaches to Associations of Rural Women in Colombia and the \\ Ethical-Political Project of Social Work \\ Abordagens às associações de mulheres rurais da Colômbia e ao \\ projeto ético-político do Serviço Social
}

Recibido enero 23 de 2019. Aceptado septiembre 21 de 2019.

\begin{abstract}
- Para citar este artículo:
Para citar este artículo: Chamorro-

Caicedo, Luz-Stella (2020).

Acercamientos a asociaciones de

mujeres campesinas en Colombia y

proyecto ético-político del Trabajo

social Ánfora, 27(48), 197-222. DOI:

https://doi.org/10.30854/anfv27.n48.2020.674

Universidad Autónoma de

Manizales. ISSN 0121-6538 /

e-ISSN 2248-6941
\end{abstract}

Luz-Stella Chamorro-Caicedo** https://orcid.org/0000-0001-9052-020X

Colombia

\section{Resumen}

Objetivo:esteartículoesunaRevisióndeantecedentes que se deriva de una investigación e intervención con mujeres campesinas en acompañamiento a grupos asociativos en el departamento de Nariño. Se trata, entonces, de analizar diversas experiencias de las mujeres rurales en Colombia sobre las prácticas de resistencia que involucran principios de gobierno de los comunes y que estas asociaciones se presentan como estrategias de resistencias para la reivindicación de la identidad de la mujer campesina y su posicionamiento político en la deconstrucción de la desigualdad económica y de la violencia estructural. Metodología: se aplicó revisión documental en las principales bases de datos como Ebosh, Proquest y Redylac, con el fin de recopilar la información actualizada sobre el objeto de estudio, con criterios de calidad. Resultados: se logró

\footnotetext{
* Artículo de revisión que retoma la indagación de asociaciones de campesinas en Colombia en Relación con proyectos productivos y los retos que enfrentan para la construcción de equidad en los contextos rurales de Colombia en las nuevas tendencias por la construcción de paz. Esta revisión hizo parte de la experiencia laboral de la autora con comunidades campesinas en el departamento de Nariño.

** Magíster en Gerencia y práctica del desarrollo. Trabajadora social. Docente de la Universidad de Caldas. Correo: luz.chamorroc@ucaldas.edu.co
} 
sintetizar tres apartados a partir del material que se recopiló: 1) retos de los campesinos en el marco de los acuerdos de La Habana, 2) las asociaciones de mujeres campesinas, 3) el proyecto ético y político de Trabajo Social. Conclusiones: se concluye que, si bien las propuestas tuvieron sentidos económicos o de memoria, siempre hay que tener un enfoque integrador que ponga en perspectiva de género lo económico y lo político en conversación con lo cultural. Desde allí, la praxis reflexiva del trabajador social debe incidir en la construcción de estas asociaciones con el fin de posicionar a las mujeres, en especial en contextos rurales aún afectados por las violencias.

Palabras-clave: Mujeres rurales; Construcción de paz; Trabajo social.

\section{Abstract}

Objective: this review article derives from research and intervention with rural women in support of associative groups in the department of Nariño. It analyzes various experiences of rural women in Colombia about resistance practices that involve principles of government of the commons and that these associations are presented as resistance strategies for the claim of identity of rural women and their political positioning in the deconstruction of economic inequality and structural violence. Methodology: a documentary review was conducted in the main databases such as Ebosh, Proquest and Redylac, in order to collect updated information on the object of study, with quality criteria. Results: it was possible to synthesize three sections based on the collected data: 1) challenges of the peasants in the framework of the Havana agreements, 2) associations of farmer women, 3) ethical and political project of social work. Conclusions: Although the stated proposals made sense with regards to economics or memory, it is always necessary to have a comprehensive approach from the economic and political perspective in a gender-based perspective related to culture. From there, the reflexive praxis of the social worker must influence the construction of these associations in order to position women, especially in rural contexts still affected by violence.

Keywords: Rural women; Peace building; Social work.

\section{Resumo}

Objetivo: este artigo éuma Revisão de Antecedentes que deriva de uma investigação e intervenção com mulheres rurais em apoio a grupos associativos no departamento de Nariño. Trata-se de analisar várias experiências de mulheres rurais na Colômbia sobre 
práticas de resistência que envolvem princípios de governo dos bens comuns e que essas associações são apresentadas como estratégias de resistência para reivindicar a identidade das mulheres rurais e suas comunidades, posicionamento político na desconstrução da desigualdade econômica e da violência estrutural. Metodologia: a revisão documental foi aplicada nas principais bases de dados como Ebosh, Proquest e Redylac, a fim de coletar informações atualizadas sobre o objeto de estudo, com critérios de qualidade. Resultados: foi possível sintetizar três seções com base no material coletado: 1) desafios dos camponeses no âmbito dos acordos de Havana, 2) associações de mulheres agricultoras, 3) projeto ético e político do Serviço Social. Conclusões: conclui-se que, embora as propostas tenham sentidos econômicos ou de memória, é sempre necessário ter uma abordagem integrativa que coloque a perspectiva econômica e a política na perspectiva de gênero em conversas com o cultural. A partir daí, a práxis reflexiva da assistente social deve influenciar a construção dessas associações para posicionar as mulheres, principalmente em contextos rurais ainda afetados pela violência.

Palavras-chave: Mulheres rurais; Construção da paz; Trabalho social. 


\section{Introducción}

Este artículo de Revisión se propone un acercamiento a las asociaciones de mujeres campesinas ${ }^{1}$, sus movilizaciones y las estrategias que han construido para posicionar su territorio, su territorialidad y su identidad. Pensar en las mujeres campesinas es abordar el contexto histórico y político en el que actualmente se encuentran inmersas dado que, históricamente, las mujeres han sido violentadas, despojadas y no han tenido igualdad de oportunidades para el acceso a tierra, capital y trabajo.

En ese sentido, acercarse a las asociaciones de las mujeres campesinas es comprender las relaciones históricas de ellas en el campo, las consecuencias causadas por el conflicto armado y las resistencias que han movilizado en transición a un escenario de postconflicto. Así pues, el trabajo social como una profesión que se ocupa de las interacciones sociales, procesos y estructuras debe comprender la subjetividad de las mujeres, sus experiencias, sus luchas por el reconocimiento y las movilizaciones colectivas por la justicia y reparación; todas estas dinámicas comprendidas bajo la desigualdad de género, aquella que también es política y económica.

Según datos del Departamento Nacional de Planeación (citado por Gonzales, 2015) se estima también que "en los municipios rurales y rurales dispersos, la mitad de la población es pobre por ingresos, independientemente si viven en la cabecera o en zonas dispersas" (p. 5). Tales condiciones de pobreza y desigualdad se exacerban cuando las mujeres son víctimas de constantes violencias y, en consecuencia, el Estado debe materializar acciones más puntuales y realizar seguimiento constante de las acciones.

Según la Convención para la Eliminación de todas las Formas de Discriminación contra la Mujer, CEDAW (2019). "la Agencia de desarrollo rural reporta que en el periodo 2012-2015 recibió 1.420 proyectos para cierre financiero y administrativo con participación total de 8.550 mujeres. Sin embargo, no es claro el porcentaje de proyectos adjudicados a mujeres rurales" (p.12).

En la implementación del acuerdo de paz firmado en La Habana la participación de mujeres campesinas es un punto explícito del capítulo de la reforma rural integral, porque históricamente se han enfrentado a las desigualdades económicas, políticas y de género. El acuerdo ubica disposiciones que les permita la garantía de sus derechos como: a) vivienda, b) seguridad para el ejercicio de la

1. Centra su interés en mujeres campesinas y las pone en la cuestión social no porque todos los campesinos no atraviesen condiciones de desigualdad, sino porque las mujeres en contextos rurales enfrentan diversas violencias que son estructurales como el patriarcado y, de ahí, también sus desigualdades económicas y políticas. 
política, c) participación en el esclarecimiento de la verdad, la convivencia y la no repetición, entre otros temas (Bautista, 2016, p. 123).

No obstante, hasta el momento, este proceso ha presentado dos inconvenientes: el primero, "la convocatoria para la participación de las mujeres rurales en la elaboración de los PDETS $^{2}$ se realizó a título personal. Las mujeres no fueron citadas como representantes de organizaciones" (CEDAW, 2019, p.16). Otro de los problemas, es que la materialización del acuerdo requiere del enfoque de género en su complejidad, pero lo que prima es la mujer como actor político en la construcción de paz, desdibujando su participación en la movilización de estrategias locales de economía.

El Censo Nacional Agropecuario (Departamento Nacional de Estadística [DANE], 2014), muestra que el 31,9\% de los hogares en el campo tienen jefatura familiar femenina y el $36.6 \%$ de la producción agrícola del país está en manos de las mujeres. La desigualdad para las mujeres en ingresos está relacionada con el control sobre la propiedad, el acceso al capital y la administración de sus unidades de producción agropecuaria (UPAS). En relación con este factor, el DANE informa que

del total de UPA con solo mujeres productoras, el 78,4\% tienen menos de 5 ha, y ocupan el 9,5\% del área. Mientras que donde los hombres son productores las UPA de menor tamaño, los hombres tienen mayor participación $(66,8 \%)$ y área $(4,9 \%)$. Un dato relevante y es que del total de las UPA con mujeres que toman decisiones de producción, más de la mitad $(52,7 \%)$ se encuentra en los departamentos de Boyacá, Nariño, Cundinamarca y Cauca (DANE, 2014, p. 1).

Entones, por una parte, al no ser dueñas del capital, tierra o trabajo hace que su incidencia administrativa sea mucho menor a la del hombre; por supuesto, esto tiene que ver con las construcciones patriarcales. Por otra parte, la economía del cuidado tiene dinámicas complejas cuando se habla de la mujer rural; esta economía se refiere al trabajo no remunerado que se realiza en el hogar como el mantenimiento de la vivienda, la atención a otras personas en el hogar o la comunidad y el aporte por mantener la fuerza remunerada de trabajo (Ministerio de Salud y Protección Social, 2016).

Los datos de la encuesta nacional de uso del tiempo presentan que los hombres ocupan "en promedio 3 horas 6 minutos en el trabajo no remunerado, mientras que las mujeres 8 horas 12 minutos, con esto se infiere que las mujeres ocupan 5 horas 6 minutos día promedio más que los hombres en este tipo de actividades” (Ministerio de Salud y Protección Social, 2016, p. 3). Así mismo, “de 
su jefatura dependen niñas, niños y adultos mayores” (Mujer campesina. Nariño, 2015, comunicación personal).

En Colombia, las mujeres rurales "ganan solo tres cuartas partes de lo que gana el hombre (...), están sobre representadas en el sector informal y en actividades económicas con bajo valor agregado. Lo que conlleva menores ingresos laborales y una menor capacidad de incrementar sus rentas totales para salir de la pobreza" (Botello y Guerrero, 2017, p. 42). En efecto, cuando se habla de mujer rural no se puede obviar sus desigualdades económicas, además de los hechos victimizantes provocados por el conflicto armado a los que han estado expuestas.

De las 8.493.100 víctimas registradas en Unidad para la Atención Integral de las Víctimas (2019) el 51\% son mujeres en su mayoría de procedencia rural. Por su parte, para las mujeres víctimas que están en proceso administrativo para la restitución de tierras se contempla actualmente un "50/50 en los procesos administrativos para la restitución cuando a principio del programa eran solo los hombres quienes se acercaban a reclamarlas" (Secretaría Distrital de la Mujer, 2017, p. 3). La Unidad de Restitución de Tierras (2019) reporta que 34.245 mujeres reclamaron su predio en tanto que los hombres fueron 49.178. Se puede apreciar, entonces, una gran diferencia que pueden enfrentar las mujeres en asuntos de acceso a la tierra. Estas desigualdades se exacerban la deshumanización del conflicto armado sobre las poblaciones rurales:

la deshumanización e invisibilización política de la población campesina ha sido un ingrediente importante de las masacres cometidas en el conflicto armado, las cuales en muchos casos llevaron al abandono y despojo de tierras, pero se mantuvieron invisibles durante largo tiempo para la política nacional. Incluir los conceptos de dignidad y proyecto de vida en el análisis permite combinar lo material y lo moral, las condiciones de vida objetivas y las subjetividades afectadas en el pasado, y a la vez proyectarlas hacia el futuro. Pero esto no es suficiente, pues hace falta conectar estos conceptos a un análisis de género (Meertens, 2016, p. $35)$.

En este orden de ideas, el presente artículo procura retomar una lectura de las organizaciones de mujeres campesinas en Colombia y cómo estas se expresan en la construcción de iniciativas de paz, a través de proyectos productivos y las luchas por el reconocimiento desde sus acciones colectivas para poner la economía al servicio y bienestar de sus comunidades. Se presenta como hipótesis que el proyecto de vida de las mujeres debe tener un enfoque integral entre lo político, lo social y lo económico y, que para el caso de las mujeres rurales, es también de género (Meertens, 2016). 
Ahora, si se pretende reactivar económicamente las zonas rurales donde las mujeres se conciban como sujetos éticos y políticos, en primera instancia, habrá que comprender los sentidos que las han movilizado desde su identidad campesina. En este contexto, pensar la economía de estas mujeres según el trabajo social va más allá de una estrategia cooperativa o productiva, sino que apunta a su reivindicación como sujetos políticos en el territorio, donde las asociaciones y cooperativas se ponen al servicio de sus acciones políticas.

\section{Metodología}

Se rastrearon documentos relacionados con las asociaciones de mujeres rurales en Colombia que han logrado incidir en procesos asociativos y productivos. Para tales efectos, se tomaron documentos del DANE, en especial el Censo Nacional Agropecuario, informes del Ministerio de Agricultura, informes del Departamento Nacional de Planeación del 2017, artículos de la revista Semana rural, tesis de maestría realizadas en la Universidad de los Andes y artículos o reportes de investigación de la revista Análisis político de la Universidad Nacional; además, se hizo revisión de artículos de la Revista Cuadernos de desarrollo rural donde su principal población fueron las mujeres rurales. Estos artículos se consultaron en bases de datos como Ebosh, Proquest y Redylac.

\section{Resultados}

Los resultados se sintetizan en tres partes: 1) retos de los campesinos en el marco de los acuerdos de La Habana, 2) Asociaciones de mujeres campesinas y 3) proyecto ético y político de Trabajo Social.

\section{Retos para los campesinos en el marco de los acuerdos de La Habana}

La reforma rural integral para la reactivación del campo contempla los siguientes principios: a) transformación estructural, b) desarrollo integral del campo colombiano, c) igualdad y enfoque de género, d) bienestar y buen vivir, e) priorización, f) integralidad, g) restablecimiento, f) regulación de la propiedad, entre otros (Santos y Jiménez, 2016). Para que estos principios se materialicen es importante concebir: 
estímulos a la economía solidaria y cooperativa: con el propósito de estimular diferentes formas asociativas de trabajo de o entre pequeños y medianos productores y productoras, basadas en la solidaridad y la cooperación, y que promuevan la autonomía económica y la capacidad organizativa en especial de las mujeres rurales y fortalezcan la capacidad de los pequeños productores y productoras de acceder a bienes y servicios, comercializar sus productos y en general mejorar sus condiciones de vida, de trabajo y de producción, el Gobierno Nacional creará e implementará el Plan Nacional de fomento a la economía solidaria y cooperativa rural (Mesa de Conversaciones, 2016, p. 28).

El Acuerdo pactado en La Habana busca fortalecer estrategias para la economía familiar, comunitaria, cooperativa y solidaria en el campo. Esta estrategia se divide en 4 ejes: i) asistencia técnica agropecuaria, ii) fortalecimiento de las capacidades productivas iii) canalizar la economía cooperativa y iv) apoyo a medidas diferenciales a las organizaciones comunitarias (Santos y Jiménez, 2016). También se definió que estos ejes lograrán la reactivación del campo (Vargas, 2018). El primer eje, se enfoca en el fortalecimiento de una asistencia técnica que elabore los costos de producción y fortalezca las prácticas agropecuarias y agroindustriales de los campesinos.

De acuerdo con el último censo agropecuario sólo el 10\% de los campesinos reciben asistencia técnica (Revista Semana, 2015). La segunda estrategia se enfoca en la generación de ingresos considerando la vocación de uso de suelo y del apoyo crediticio para tener acceso a cadenas de valor sostenibles ${ }^{3}$; sin embargo, esta estrategia está supeditada a la asociación de los campesinos, pues en la medida en que se asocian logran una figura jurídica que les permite incrementar el crédito y acceder a créditos blandos de producción agroindustrial por medio de la línea FINAGRO4. Ahora bien, materializar este punto dependerá de que la gobernabilidad local construya asociaciones y sentidos comunes para el campo.

Las últimas estrategias se refieren a la facilidad de comercio de bienes y transacciones que pretenden fortalecer las organizaciones sociales comunitarias de base para que puedan implementar servicios y recursos para la generación de ingresos. Sin embargo, el proceso de gestación de una cooperativa o de una

\footnotetext{
3. La cadena de valor es el conjunto de recursos y actores que participan de una transacción. Los análisis de cadena de valor son útiles para comprender si existen diferencias en la configuración (actores, recursos, etc.) de la cadena de valor entre los bienes básicos y los diferenciados. No obstante, estos análisis no permiten develar la distribución del valor en el tiempo para cada uno de los actores (Rueda, 2016, p. 51).

4. Fondo para el Financiamiento del sector Agropecuario(2018): es una entidad que promueve el desarrollo del sector rural colombiano con instrumentos de financiamiento y desarrollo rural, que estimulan la inversión. Es una sociedad de economía mixta del orden nacional, organizada como establecimiento de crédito, con régimen especial, vinculada al Ministerio de Agricultura y Desarrollo Rural y vigilado por la Superintendencia Financiera de Colombia (FINAGRO, 2018).
} 
asociación requiere de construir objetivos y sentidos comunes en relación con la participación democrática, la formación y educación de los asociados, el apoyo entre asociaciones o grupos cooperativos, la autonomía e independencia y el compromiso con la comunidad; todos estos sentidos superan una simple participación económica y eso es lo habría que abordar, sin decir que lo económico no sea relevante (Confederación de Cooperativas de Colombia [CONFECOOP], 2018).

En el capítulo de la reforma rural integral, aunque la mujer rural está enunciada como un actor político relevante, también se desdibuja porque la ponen en iguales consideraciones a hombres. Es necesario comentar que, si bien el acuerdo para la terminación del conflicto armado es necesario y un ejemplo internacional, se espera que las gobernabilidades locales no caigan en decisiones que incrementen la vulnerabilidad de los campesinos y de las mujeres, como sucedió con Agro Ingreso Seguro. La contraloría en su informe sobre la ejecución de la política de vivienda de interés social para poblaciones rurales comenta que:

la asignación de recursos para el subsidio de vivienda de interés social rural está por debajo del tope mínimo legal establecido, la falta de lineamientos por parte del Ministerio de Agricultura y Desarrollo Rural para la distribución de los recursos del subsidio de vivienda rural que otorgan las Cajas de Compensación Familiar, y la ausencia de demanda de la línea de crédito de Finagro por las restricciones de acceso que éste ofrece a la población rural de bajos ingresos, entre otros aspectos, ha comprometido durante la última década el derecho a la vivienda digna de quienes habitan en las zonas rurales del país (Contraloría General de la República, 2016, p. 28).

Las condiciones del clientelismo local que se teje en las periferias del país han limitado la efectividad de que la población rural acceda a bienes y servicios que podrían mejorar su producción o sus condiciones de vivienda digna o sus fuentes de ingreso con el pago por servicios ecosistémicos; en estas condiciones las principales afectadas también son las mujeres rurales (Delgado, 2014). Por eso, Uribe (2012) concluye que la nueva agenda redistributiva debe dignificar al campesino: "el rasgo principal del estilo de desarrollo ha sido la persistencia de desigualdades extremas no solo en la distribución de la riqueza y del ingreso, sino también en la asignación del respeto y el reconocimiento social (Uribe, 2012, p. 507). En ese escenario no sólo basta con la redistribución sino considerar a la mujer campesina también como una identidad colectiva que merece reconocimiento en condiciones de justicia social.

La paz, como un proceso, imperfecto requiere además de instituciones sólidas fortalecidas. A este respecto, Robinson (2016) sostiene que el fracaso de 
las naciones es por la debilidad de sus instituciones económicas y la ausencia de una ética en cuanto a la gobernabilidad (p. 57). Ahora, "las regiones que tienen instituciones económicas 'extractivas', que no crean incentivos de base, crearán pobreza. Las instituciones económicas incluyentes, que sí crean incentivos y oportunidades, generarán prosperidad" (Acosta, 2012, p. 2).

De otra parte, Vargas (2017) ha contemplado retos políticos como: a) el despliegue territorial del Estado que se ve afectado por la fragilidad institucional donde algunas élites podrían bloquear la implementación del acuerdo; b) las deseconomías de escala, porque hay un proyecto de urbanización del campo y, por ello, los autores plantean como recomendación c) fortalecer los consejos municipales de desarrollo rural (Vargas y Hurtado, 2017). Esta última propuesta es que cada municipio debe garantizar presupuestos participativos, de tal manera que los ciudadanos ubicados en la zona rural y zona rural dispersa puedan tener una mejor distribución para inversión en el campo (Vargas y Hurtado, 2017).

Si bien los análisis de Vargas y Hurtado (2017) son claros y pertinentes, no es evidente su focalización en las mujeres campesinas; sus análisis son generalizados a todos los campesinos, pero hay que reconocer que todos se encuentran en dinámicas de desigualdad. Además, habría que considerar el conocimiento de los campesinos sobre los espacios de representación para la toma de decisiones. Así las cosas, al parecer la movilización y la participación de los campesinos no subyace únicamente en la construcción de instituciones locales, sino en cómo se articulan las instituciones del Estado con la gobernanza de las asociaciones de base las cuales, con sus movilizaciones, logran posicionar sus demandas en espacios públicos de incidencia.

\section{Asociaciones de mujeres campesinas}

Las asociaciones que aquí se citan cumplen con una característica en la cual la tierra es el contexto en donde convergen múltiples intereses de las mujeres. La tierra, siguiendo a Meertens (2000), se entiende como "una metáfora para indicar todos los elementos que en diferentes momentos del siglo XX han constituido la cuestión agraria: las formas de explotación, los debates políticos, las luchas por los derechos a la tierra y las formas de organización de resistencia campesina” (p. 32). Han sido las organizaciones de mujeres campesinas las que se han movilizado para construir una cultura de paz que las dignifique y las posicione en su territorio. Las movilizaciones campesinas se comprenden como redes con sentidos de organización y diversidad cultural, con carácter político/ cultural y con múltiples actores, espacios culturales e institucionales. Las mu- 
jeres campesinas han construido desde su cotidianidad diversas maneras de ser resilientes ante la violencia. Dice Meertens (1994) que

en la trayectoria de vida de las mujeres las hace más sensibles a la destrucción del tejido social, de cómo son las mujeres las que cargan con la supervivencia económica, social y emocional de la familia... en fin, de cómo son ellas las que cargan con ese dolor de enfrentar las secuelas que se generan, sin estar preparadas para ello y sin haberlo propiciado. Es en ese terreno donde se confunden a veces los papeles de víctimas y de nuevos sujetos sociales, aunque no podemos olvidar que esos nuevos papeles son asumidos en unas circunstancias de extrema adversidad (p. 3).

La asociación como una estrategia para volver sobre el tejido social en el territorio es un espacio de escucha, de resiliencia y de pensar un proyecto de vida a futuro. Aquí, cuando cada mujer decide ser parte de la asociación, la gobernanza de los comunes y la participación se convierten en ejes de transformación de su contex to inmediato.

Por su parte, Ostrom (2002) problematiza la administración de los bienes comunes o recursos de uso común, a partir de los cuales las personas construyen cooperación, trabajo en equipo y solidaridad; para que la administración de los comunes tenga impactos deberá entonces diseñarse bajo "límites claramente definidos, coherencia de apropiación y provisión de las condiciones locales, acciones colectivas negociadas, supervisión, sanciones graduadas, mecanismos para la resolución de conflictos, reconocimiento mínimo de derechos de la organización, y entidades anidadas" (Ostrom, 2002, p. 92).

Las asociaciones de mujeres campesinas surgen como una salida a la violencia estructural política, económica y cultural y, por tanto, sus movilizaciones son por los derechos de las mujeres en donde involucran también a los hombres, como lo comentan Puigvert y Muñoz (2012): "los hombres como las mujeres necesitaban ser educados sobre los derechos de las mujeres y ver más claramente que la violencia nunca era una respuesta a un problema dentro del hogar o en cualquier otro lugar" (p. 8).

Ahora bien, las asociaciones de mujeres tienen tres dimensiones: a) económica que garantiza su autonomía financiera, b) política que reivindica sus derechos y toma de decisiones y c) subjetiva porque representa la valoración de sí misma que merece vida digna y justa (Stromquist, 2015). En ese sentido, la mujer como sujeto político ha significado trascendencia y participación más allá de un derecho que está en la Constitución Política de Colombia y las asociaciones se han convertido en espacios en los que las campesinas son capaces de ejercer una actividad política. 
Trabajos como el de Ostrom (2002) detallan que las organizaciones locales pueden construir relaciones de solidaridad que son económicas y que involucran tres ejes centrales: 1) administración responsable y de beneficios para todos los que participen en ella y 2) gerencia de prácticas locales evidentes por a) la responsabilidad y la honestidad, b) el respeto para dirimir los propios conflictos, c) la solidaridad y d) sentido de pertenencia a la agroindustria, y 3) una posición política de las comunidades para la apropiación del territorio y el cambio de las dinámicas relacionales del contexto.

En el análisis de antecedentes y búsqueda de organizaciones de mujeres campesinas que cumplan con estos principios se encontraron diversas asociaciones que además de cumplir con los principios develados por Ostrom (2002) han posicionado desde sus acciones colectivas prácticas de resistencia política, económica y social para permanecer en el territorio.

\subsection{Prácticas de resistencia para permanecer en el territorio.}

Isabela Marín autora del proyecto de investigación "Movilización de las mujeres rurales del suroccidente colombiano" 5 cita tres grupos importantes de mujeres campesinas, dos de cuales han consolidado un enfoque de movilización cultural a través de proyectos productivos y, el tercero, se enfoca en el acompañamiento de mujeres que han sido víctimas de la violencia patriarcal.

ASMUCAM, una asociación que nació en 2005 cuando algunas mujeres de los otros municipios de Nariño contactaron a las que ahora son líderes de la asociación, haciendo un intento de invitarlas a formarse en derechos humanos de las mujeres (Marín, 2013, p. 32). Uno de sus grandes resultados asociativos fue la consolidación de proyectos productivos. Las mujeres relatan que tenían la idea de desarrollar de manera colectiva proyectos que generen ingreso para ellas y sus familias. Si bien la asociación se conformó con el propósito de que las campesinas puedan reivindicar su lugar como actores políticos, las mujeres campesinas a lo largo de sus tránsitos construyen una identidad que dignifica al campesino desde su construcción histórica y desde las responsabilidades heredadas para la protección de la tierra siendo ejemplo para las generaciones futuras.

Marín (2013) también menciona que la organización de mujeres campesinas de Inzá Cauca, ha liderado procesos de resistencia y reconciliación en el territorio. Lo que hizo esta organización fue interpelarse sobre cómo vivían las mujeres y cómo solucionar los problemas que tienen, para empezar a capitalizarlos y

\footnotetext{
5. Proyecto de tesis elaborado para optar al título de Magíster en Ciencias políticas en la Universidad de los Andes. El proyecto de investigación tomó como referencia tres organizaciones de mujeres: a) ASMUCAM (Sandoná, Nariño), b) Mujeres de Inzá Cauca y c) Mariposas de alas nuevas (Buenaventura) (Marín, 2013).
} 
enseñar cómo se pueden resolver la situación (p. 46). Su mayor logro es la reivindicación de la participación y la construcción del fondo de créditos para mujeres, que son otorgados a aquellas mujeres que diseñen su proyecto y lo implementen en el territorio.

Esta organización reclamó el lugar de la mujer en ámbitos privados, inclusive develando que las dinámicas de violencia intrafamiliar no pueden ser abordados exclusivamente por mujeres, el surgimiento de nuevas feminidades requiere de la resignificación con la participación de las masculinidades.

Para finalizar Marín (2013) cita a Mariposas de Alas nuevas, organización de mujeres radicada en Buenaventura, cuyo propósito elemental es reflexionar con otras mujeres sobre la violencia y activar una ruta de seguimiento para vincularlas a proyectos productivos. Dadas las condiciones de violencia de Buenaventura, las mujeres son constantemente vulneradas porque se asocia el cuerpo de la mujer como parte del territorio y, por consecuencia, su cuerpo pertenece a los grupos armados y las intimidaciones que estos ejecutan por tener el control (Marín, 2013).

Esta propuesta ha sido un acompañamiento constante a las víctimas de diversas violencias, a la escucha y al cuidado de la mujer en Buenaventura; una de sus grandes estrategias ha sido el anonimato porque ello le ha permitido entrar en las voces de las mujeres y detectar quiénes son víctimas o propensas a la violencia intrafamiliar.

Analizar las asociaciones de las mujeres campesinas es interrogarse constantemente por la identidad de ellas y el contexto rural en el que se gesta. Estos tres ejemplos, nacen al deconstruir el lugar de la mujer a la cual ha sido sometida por dinámicas del patriarcado y de las múltiples violencias que existen en los territorios con actores armados; por tanto, posicionar el lugar de la mujer ha sido una constante en estas tres organizaciones:

la transgresión de roles y espacios limitantes significa una ruptura con la percepción habitual de impotencia frente a los problemas, y puede generar efectos de emancipación. Por esta razón, desde una perspectiva de género, los procesos de empoderamiento espacial -en un sentido material como propiedad de la tierra y en un sentido simbólico como visibilidad en espacios discursivos- son de particular interés y relevancia (Hoinle, Rothfuss y Gotto, 2013).

En la revisión de antecedentes se encontraron organizaciones de mujeres campesinas que, no se constituyeron por pensar su identidad femenina, pero se 
consolidaron por un interés en la construcción de proyectos de agroindustria para construir equidad económica en sus contextos. Y si bien las prácticas agroecológicas han sido claves para su movilización, se podría inferir como hipótesis que estas prácticas obedecen también a una identidad de mujer campesina.

Zuluaga y Arango (2013) destacan en Antioquia a la Asociación de Mujeres Organizadas de Yolombó (AMOY). Esta es una organización de mujeres campesinas que viven en contextos de agricultura familiar "donde predomina la producción de cultivos de caña y de café en pequeños predios. Las campesinas desde su organización han construido una resistencia desde la agroecología como estrategia de resiliencia y de sobreponerse a las dinámicas del conflicto armado” (Zuluaga y Arango, 2013, p. 2). La organización de mujeres campesinas, como las ya mencionadas, no han sido ajenas a la violencia estructural, que se comprende como la fuerza en contra de los pobres y de las poblaciones más desfavorecidas en los procesos económicos y políticos.

estos procesos y estas fuerzas constituyen la base de la 'violencia estructural', una violencia de intensidad constante que puede tomar varias formas: racismo, sexismo, violencia política, pobreza y otras desigualdades sociales. A través de la rutina, del ritual o de los transcursos difíciles de la vida, esta violencia estructural pesa sobre la capacidad de las personas para tomar decisiones sobre sus vidas (Zuluaga y Arango, 2013, p. 3)

En estos territorios también es evidente una violencia contra los bienes comunes asociados al medio ambiente, desde esta organización la agroecología se convierte en una práctica sustantiva de alimentación y del uso responsable y sostenido del capital ecológico; por tanto, la agricultura familiar se destaca por una concepción de vida: "la producción se hace en los predios de cada una de las familias, sin agroquímicos, con semillas nativas, en sistemas de policultivos y con algunas tecnologías apropiadas que buscan un uso y manejo óptimo y racional de los recursos” (Zuluaga y Arango, 2013, p.7).

Otro movimiento de mujeres campesinas denominado Asociación de mujeres Anoriseñas, quienes empezaron su movilización en 1999 y han acompañado el fortalecimiento de los derechos de las mujeres: "desde el 2009 la organización hace parte de la red Colectivo de Mujeres del Nordeste y a partir del 2009 la organización entra en un proceso de consolidación organizativo, productivo y social impactando en la conformación de grupos veredales” (Martínez., 2018, p. 8). En Colombia, los análisis se han centrado más en los procesos de cadenas de valor industriales o agroindustriales, pero el análisis no se ha enfocado en develar la desigualdad económica que podría haber en los eslabones de las cadenas de 
valor donde participan las mujeres, y cómo sus organizaciones se desenvuelven de acuerdo con los grupos de interés que persigan sus objetivos ${ }^{6}$.

Por su parte, la investigación de Giraldo (2010) reconoce organizaciones de mujeres campesinas que se destacan en la agroindustria que permita construir cadenas de valor en condiciones de justicia social y equidad. Las experiencias exitosas que se han mencionado tienen un punto central y es que todas estas nacieron por acción colectiva comunitaria y no por la acción de los gobiernos locales y regionales en el territorio. El impacto de las agroindustrias de mujeres campesinas es evidente en la capacidad de gestión de proyectos sociales que movilizan liderazgos y oportunidades para su desarrollo humano y social, entendido este como el bienestar aquí y ahora (Giraldo, 2010).

Ahora, algunas de las organizaciones de mujeres campesinas que cumplen con las condiciones de resistir a través de una agroindustria fueron: "Asocañabraval, Asomcalá, Amurabi, Asomural, Malavar, Rosalita, Asmucicot, Natalí, y Artesguavio, las cuales están ubicadas en los municipios de Caparrapí, Guaduas, Bituima, La Mesa, Pandi, El Rosal, Cota, Ubaté y Gachetá” (Giraldo, 2010, p. 45). Todas estas organizaciones se han caracterizado porque los sentidos que movilizan la acción colectiva terminan siendo superiores al interés individual y aunque estas organizaciones se han visto fragmentadas por el conflicto armado, también se han visto fortalecidas porque han posicionado a las mujeres como líderes en sus contextos, donde fraguan las luchas por el reconocimiento (Fraser y Honneth 1, 2006). Se podría inferir, entonces, que si bien estas organizaciones se enfocaron en asuntos productivos, tienen en sus organizaciones una característica que posiciona a la mujer rural: "el ser rural juega un papel central en la auto-representación y especialmente en lo que respecta a cómo quieren ser identificadas por quienes son sus interlocutores/as externos/as" (Viera, 2012, p. 351$)$.

\section{Proyecto ético y político de Trabajo Social en contexto de comuni- dades rurales}

Las interacciones sociales de mujeres campesinas y las desigualdades históricas a las que han sido sometidas son, por una parte, la conjugación de contex-

\footnotetext{
6. Es importante que toda política pública para mujeres en contextos rurales contemple acciones positivas. Como lo comenta Parada (2018), "esta acción opta por reconocer las diferencias sociales que existen entre hombres y mujeres, y sobre ellas diseñar mecanismos que eliminen las barreras o garanticen unas condiciones mínimas para que las mujeres accedan a la distribución de recursos en materia educativa, laboral, crediticia y de participación, entre otros" (p. 125).
} 
tos y violencias en las zonas rurales de Colombia. Por otra parte, representan una oportunidad para comprender sus relaciones con la tierra, sentidos que superan lo económico, sin dejar que este sea menos importante.

En ese escenario, el Trabajo social, con base en la construcción de procesos de intervención, construye un proyecto ético y político entendido como una apuesta orientada bajo los principios de dignidad, justicia social, equidad y derechos humanos; un proyecto que implica la toma de decisiones, acciones políticas y movilizaciones con grupos de interés, con el fin de dignificar al campo y, por tanto, a la mujer campesina, tomando como principal referente sus saberes en contexto y su configuración histórica como sujetos políticos e siendo consciente de ellas como sujetos históricos con capacidad de decisión y en constante diálogo para hacer consciencia de su identidad colectiva y territorio.

Siguiendo a Badiou (2015), "no resistir es no pensar. No pensar es no arriesgarse a arriesgar. Hay que arriesgarse a enunciar la situación, por lo que ella es, en cada caso, y luego arriesgarse a que haya riesgos” (p. 30). Tomar el riesgo de enunciar la identidad de la mujer campesina que se teje en múltiples escenarios resistiendo dialógicamente y constructivamente en iniciativas de paz.

De acuerdo con Aquin (2005) "Si las intervenciones profesionales implican un momento de justificación de nuestras elecciones con base en lo que consideramos justo y bueno, entonces la dimensión ético-política seguirá constituyendo un componente ineludible de nuestras discusiones y de nuestras acciones" ( $\mathrm{p}$. 75). Por tanto, entender las asociaciones de las mujeres campesinas representa dos puntos fundamentales desde el Trabajo social: 1) interpretar desde la reflexividad el contexto histórico del país de cara a sus compromisos con las poblaciones rurales afectadas por el conflicto armado y otras violencias, máximo cuando desde la gobernabilidad ha sido difícil la implementación de los acuerdos y, por consiguiente, las iniciativas de paz de las comunidades locales son claves; y 2) la ética y la concepción de justicia social que orientan al trabajo social en reconocer la configuración de la identidad de la mujer campesina (Leal y Malagón, 2015).

En relación con el primer punto, la superación de la desigualdad no implica una solución técnica del trabajador social sino de la comprensión de la mujer campesina en su contexto histórico, político, económico y familiar. Siguiendo a Shön (1992): “cuando una situación problemática es incierta, la solución técnica del problema depende de la construcción previa de un problema bien definido, lo que en sí mismo no es una tarea técnica” (p. 4).

Sobre el segundo punto, la justicia social como reconocimiento de las identidades colectivas plantean que las asociaciones de mujeres campesinas son un esfuerzo por reivindicar su lugar político, social y económico para la construcción de paz desde sus memorias colectivas, en el cual el trabajo por la memoria es también resignificar las prácticas de patriarcado que se han convertido en co- 
tidianas y que orienta los proyectos de vida de muchas mujeres; esto, sin olvidar el impacto del conflicto armado en contextos rurales.

A este propósito, Cifuentes (2008) plantea que la incidencia de las mujeres va más allá de los espacios familiares, dado que supone democratización de las relaciones sociales institucionales y cómo esta democratización influye en la paridad ciudadana y, en especial, en el reconocimiento de las mujeres rurales como ciudadanos en donde su asociación supera los intereses productivos (Cifuentes, 2008). Los intereses productivos son una estrategia para construir una identidad.

El proyecto ético y político del Trabajo Social se pone en una conversación sobre lo ético, es decir, lo justo y bueno para las comunidades; también expresa el lugar político que el trabajador social asume en la construcción de paz en contextos rurales, en otras palabras, las decisiones éticas, políticas que se materializan en un proceso de intervención. Tal proyecto ético y político se fundamenta para este dilema en tres aspectos fundamentales: a) la comprensión de las dinámicas de desigualdad como objeto de intervención, b) la resistencia y organización como una práctica dialógica a fortalecer y c) la comprensión hermenéutica y crítica el territorio y la territorialidad.

En el primer componente, es importante considerar que la desigualdad no es sólo producto de condiciones macroeconómicas estructurales sino de las construcciones culturales propias de las comunidades; es decir, de cómo el patriarcado ha provocado que muchas mujeres tengan menos tierra para administrar en las UPAS, pero también de deconstruir los discursos que han naturalizado las mismas mujeres por sus procesos de socialización, donde se ratifica el poder del hombre.

El trabajador social, junto con las mujeres, rurales debe potenciar nuevas formas conscientes de movilización social, en especial en territorios donde las organizaciones y movilizaciones son escasas; así pues, el ejercicio político de las mujeres es de vinculación de los intereses de otros y la renuncia al cumplimiento de las aspiraciones individuales que sirven a fines de satisfacción instrumental (Díaz, Carmona y Montañez, 2019). Esos sentidos comunes son un claro ejemplo de que la condición política es una acción discursiva que busca la transformación económica, social y política de las mujeres, donde ellas amplíen una mirada crítica sobre sus realidades y las construcciones propias de su contexto.

En este contexto, el Trabajo social debe volcar su mirada a los microemprendimientos y estrategias cooperativas porque "muestran cómo la autonomía económica se traduce en la capacidad de tomar decisiones. No obstante, la negociación de sus identidades de género es un proceso cultural lento que apunta a transformaciones familiares y también a cambios en la comunidad" (Soto y Fawaz, 2016, p.150). 
En relación con la resistencia, esta se entiende como una acción política que se construye con propósitos de recuperar espacios políticos, por ejemplo la participación de ellas en las organizaciones. La resistencia es toda acción colectiva y ciudadana que reclama el lugar como mujeres en un territorio para dotarlo de nuevos sentidos. En tal contexto, se busca interpelar, quizás, saberes construidos, lo que implica interpelar el lugar geopolítico donde las mujeres han construido capacidades ciudadanas. Como lo comenta García (2013): "la resistencia que se articula en el 'momento frontero' y que lo hace a propósito de la reconfiguración de los espacios de representación y participación política local de una parte, y de la construcción del nuevo sujeto político" (García, 2013, p.15).

En cuanto al territorio y territorialidad, las organizaciones de mujeres campesinas consolidan un tejido social en sus interacciones sociales que dota de sentido y significado al territorio. Pudiera ser que estos sentidos si bien son económicos porque pretenden incrementar la equidad, no se agotan en el sentido económico. Hay unos sentidos que las movilizan y que superan la producción campesina como los sentidos construidos desde la huerta como una posibilidad de encontrarse, movilizarse y tomar acciones políticas (Marín, 2013); la posibilidad de construir prácticas agroecológicas de agroindustrias y la posibilidad de posicionar estas miradas solidarias de economía como una alternativa de construcción de paz territorial. En este escenario, el Trabajo social puede aportar a resignificar el tejido social y las relaciones de solidaridad:

entendemos al territorio como una construcción histórica y social, ubicada temporal y espacialmente. Dicha construcción territorial es dinámica y está inmersa en procesos de disputa continua por sujetos con agendas, acciones y estrategias diferenciadas que ejercen niveles de control desigual sobre la utilización de los recursos, los flujos sociales, las construcciones simbólicas y las proyecciones del territorio (Flórez y Rodríguez, 2016, p. 2).

La praxis profesional orientada al campo colombiano, en especial a la construcción de equidad de género en el campo, implica hacer consciencia y transformarla, a partir de situarse en el contex to porque "la vida social cotidiana es tejido entre un yo y un tú, es un asunto intersubjetivo, aboga por la propia persona de los que están comprometidos en esa situación específica” (Aguayo, 2007, p. 50). El Trabajo social debe investigar la importancia de las mujeres rurales en la dirección con encaminar su intervención a las cooperativas agrícolas: “a pesar de que las mujeres han desempeñado un papel importante en la gestión de las cooperativas en ciertas regiones de Colombia, hay poca investigación sobre este tema. 
La cara de la Colombia rural es femenina y la perspectiva de cooperativas agrícolas autosostenibles también puede serlo (Gutiérrez, 2014). Además, porque la resistencia no sólo es económica o política, sino que configura diversas dimensiones desde donde se enuncian. El Trabajo Social asume, entonces, una postura crítica en la comprensión de las violencias sociales y políticas que han atravesado a las mujeres rurales; de este modo, y retomando a Aquin (2003), el "trabajo social tiene en sus manos la recuperación plena del concepto de derechos sociales, sabiendo que su concreción es un compromiso colectivo y que es factible sólo a través de la acción pública y colectiva” (Aquin, 2003, p. 21).

Así pues, toda acción colectiva se enmarca en movilizar procesos dialógicos, interactivos que involucren democratización de las relaciones, que entre en la voz de lo institucional, que construya capacidades de liderazgo, movilización de redes y de recursos que favorezcan la reconstrucción de la mujer campesina como identidad, en la cual: "los actores, al definir la identidad, se definen a sí mismos y sus relaciones con otros actores de acuerdo con los recursos disponibles y con las oportunidades y restricciones del medio” (Revilla, 2010, p. 67). Reconocer a la mujer campesina como actor político desde su identidad, no invalida las desigualdades a las que ha estado sometida; por el contrario, las reconoce para tomar decisiones en favor de su identidad y de sus oportunidades económicas como lo hemos visto en las organizaciones que se analizaron en este estudio.

Para pensar la justicia social de las mujeres campesinas es menester asumir que como profesional no se puede ser neutral. La neutralidad valorativa como lo plantea Aparicio (2018) es: "un artilugio ideológico porque siempre enmascara una decisión política. Sin embargo, qué entra y qué no entra dentro de un cálculo racional siempre va a dejar por fuera cosas - externalidades, dirían ciertas escuelas de pensamiento económico. Y eso es política” (p. 1). En ese sentido, el Trabajo social debe tomar una decisión política para comprender las dinámicas que acontecen en los contextos rurales con el propósito de construir equidad para las mujeres campesinas; un proceso que movilice sus proyectos de vida en condiciones de dignidad y que, constantemente, dignifique a los campesinos.

\section{Conclusiones}

Las conclusiones se orientan a dos direcciones: 1) los sentidos colectivos y 2) praxis del Trabajo social: 


\section{Sentidos colectivos}

Se puede decir que la reforma rural integral requiere de la construcción de asociaciones de los campesinos, donde las cooperativas campesinas pueden ser un punto clave para el sector agropecuario; sin embargo, para que sea una cooperativa se requiere quizá de un trabajo colaborativo que supere inclusive las mismas asociaciones y se conviertan jurídicamente en otra figura, esto podría implicar riesgos para las asociaciones conformadas. Vale aclarar que estas organizaciones sociales pueden ser un espacio político para deconstruir la violencia y para fundamentar nuevas territorialidades que superen una única mirada que puede caer en lo económico, o sólo lo social como los actos de memoria, tomando como referencia que las dos categorías pueden ser articuladas, pero esta decisión recae puntualmente en los objetivos que cada una de las mujeres persiga al ser parte de una organización.

\section{Praxis del Trabajo Social}

El proceso de transición en postconflicto requiere que el Trabajo Social, como profesión que interpela las micro-realidades, pueda devolver su mirada al agro, en especial, develar los sentidos que asumen las mujeres campesinas en la organización social y los valores que les atribuyen a sus procesos para tener una participación política que supera la simple participación en el mercado. De igual manera, es importante no romantizar los procesos sociales, puesto que al interior de las organizaciones también se pueden esconder fragilidades en términos del liderazgo relacional, saberes que hay que deconstruir y poner en diálogo como memoria colectiva.

El mismo hecho de la asociación involucra no sólo los sentidos que las personas le otorguen a por qué y para qué asociarse, sino los estereotipos que cada persona tenga sobre la construcción de esos procesos.

El Estado debería materializar las instituciones necesarias para construir condiciones de equidad. Y si el Trabajo Social encauza sus reflexiones a la mujer campesina, valdría la pena incursionar en las cooperativas agrícolas y posicionarse desde los emprendimientos como las acciones colectivas. 


\section{Referencias}

Acosta, B. (2012). Entrevista Libro la pobreza de las naciones. ¿̨Pr qué fracasan los países? Koyuntura, 5(41), 1-8. https://www.usfq.edu.ec/publicaciones/ koyuntura/Documents/koyuntura_2014-41.pdf [Consultado el 14 de septiembre de 2918].

Aguayo, C. (2007). Las profesiones modernas: entre el conocimiento y poder. Buenos Aires, Argentina: Editorial Espacio.

Aparicio, R. (2018). Alberto Carrasquilla o cuando la técnica no es ética. 070 Política y Sociedad/Opinión. https://cerosetenta.uniandes.edu.co/etica-alberto-carrasquilla/ [Consultado el 14 de septiembre de 2018].

Aquin, N. (2003). Ensayos sobre ciudadanía. Reflexiones desde Trabajo social. Buenos Aires, Argentina: Espacio.

Aquin, N. (2005). Pensando la dimensión ética-política del TS. Revista Trabajo social, 71-83. https://aprendeenlinea.udea.edu.co/revistas/index.php/revistraso/article/view/24256 [Consultado el 19 de Agosto de 2019].

Badiou, A. (2015). Compendio de metapolítica. Buenos Aires, Argentina: Prometeo libros.

Bautista, S. (2016). Mujer rural y construcción de paz en Colombia: temas, problemas y desafíos. Revista prospectiva, 24, 121-148. http://revistaprospectiva.univalle.edu.co/index.php/prospectiva/article/view/4545 [Consultado el 14 de septiembre de 2018 ].

Botello, H.; Guerrero, I. (2017). Condiciones para el empoderamiento de la mujer rural en Colombia. Entramado, 62-70. http://www.scielo.org.co/pdf/ entra/v13n1/1900-3803-entra-13-01-00062.pdf [Consultado el 22 de octubre de 2018 ].

Cifuentes, R. (2008). La justicia a las identidades colectivas: más allá del dilema de la distribución y reconocimiento. Revista Eleuthera, 5(2), 123-138. www. redalyc.org/pdf/1290/129012573008.pdf [Consultado el 12 de septiembre de 2018]. 
Confederación de Cooperativas de Colombia, CONFECOOP. (2018). Cooperativas: un impulso económico y social al país. https://www.portafolio.co/negocios/empresas/cooperativas-impulso-economico-social-pais-44998

Contraloría General de la República (2016). Informe de Auditoría a la política de vivienda rural. https://www.contraloria.gov.co/documents / 463406/483337/Bolet\%C3\%ADn+Macro+Fiscal+14.pdf/54430f13-be3c-46e8-bd64-c2f8dfd6971b?version=1.2 [Consultado el 13 de septiembre de 2018 ].

Convención para la Eliminación de todas las Formas de Discriminación contra la Mujer, CEDAW. (2019). Primer informe sobra específico de mujeres rurales campesinas en Colombia. http://www.fiancolombia.org/wp-content/ uploads/2019/02/2.4-InformeSombraMujeresRuralesCOLOMBIA.pdf [Consultado el 19 de agosto de 2019].

Delgado, N. (2014). Estudio de profundización sobre intervenciones públicas para el fortalecimiento de capacidades institucionales de las entidades territoriales, Bogotá (Tesis de Maestría). Universidad de los Andes.

Departamento Administrativo Nacional de Estadística, DANE. (2014). Informe del Censo Nacional Agropecuario. https://www.dane.gov.co/files/images/ foros/foro-de-entrega-de-resultados-y-cierre-3-censo-nacional-agropecuario/CNATomo2-Resultados.pdf [Consultado el 14 de septiembre de 2018 ].

Díaz, A.; Carmona O.; Montañez, M. (2019). Formación de sujetos políticos. Pereira, Colombia: Universidad Tecnológica de Pereira.

Flórez, D.; Rodríguez, J. (2016). Ordenamiento territorial en Colombia: violencias, guerras y resistencias. Bitácora, 26, 37-44. http:/ /www.scielo.org.co/ pdf/biut/v26n2/v26n2aO4.pdf [Consultado el 19 de abril de 2019].

Fondo para el Financiamiento del sector Agropecuario, FINAGRO. (2018). ¿Quiénes somos? Línea FINAGRO. https://www.finagro.com.co/ qui\%C3\%A9nes-somos/informaci\%C3\%B3n-institucional\#1765 [Consultado el 14 de septiembre de 2018 ].

Fraser, N.; Honneth, A. (2006). ¿Redistribución o reconocimiento? Madrid, España: Morata-Paideia. 
García, C. (2013). Violencia, resistencias y ciudadanías en las localidades campesinas de Antiqoquia. Análisis político, 26(77), 39-56. https://revistas.unal. edu.co/index.php/anpol/article/view/43665/44945 [Consultado el 19 de abril de 2019 ].

Giraldo, O. (2010). Campesinas construyendo la utopía: mujeres, organizaciones y agroindustrias rurales. Cuadernos de desarrollo rural, 7(65), 41-57. http:// www.scielo.org.co/pdf/cudr/v7n65/v7n65a03.pdf [Consultado el 22 de octubre de 2018].

Gonzales, A. (2015). Misión para la Transformación del Campo: síntesis y algunas reflexiones. https://publicaciones.fedepalma.org/index.php/palmas/article/ view/11700 [Consultado el 4 de septiembre de 2018].

Gutiérrez, J. D. (2014). Smallholders' Agricultural Cooperatives in Colombia, vehicles for rural development? Cuadernos de desarrollo rural, 73, 219-271. https:// revistas.uniandes.edu.co/doi/abs/10.13043/dys.73.6 [Consultado el 2 de diciembre].

Hoinle, B.; Rothfuss R.; Gotto D. (2013). Empoderamiento espacial de las mujeres desde la economía solidaria. Cuadernos de desarrollo Rural, 72, 117 139. http://www.scielo.org.co/pdf/cudr/v10n72/v10n72a07.pdf [Consultado el 3 de noviembre de 2018 ].

Leal, G.; Malagón, C. (2015). Historia de trabajo social en Colombia: de la doctrina social de la iglesia al pensamiento complejo. Revista de Trabajo Social. http://www.humanas.unal.edu.co/files/cms/5976745747ed6ab3b5ceo. pdf [Cosultado el 2 de mayo de 2018].

Marín, I. (2013). Resistencias desde la huerta. Movilización de mujeres en zonas rurales del suroccidente colombiano. https://biblioteca.uniandes.edu.co/visor_ de_tesis/web/?SessionID=L1Rlc2lzXzEyMDEzMjIwMC8xODI4Ln$\mathrm{BkZg} \% 3 \mathrm{D} \% 3 \mathrm{D}$ [Consultado el 22 de octubre de 2018 ].

Martínez, V. (2018). Aportes de mujeres a la paz. (Trabajo de grado). http://tesis.udea.edu.co/dspace/bitstream/10495/10099/1/MartinezVeronica_2018_AportesMujeresPaz.pdf [Consultado el 17 de noviembre de 2018]. 
Meertens, D. (1994). Mujer y violencia en los contextos rurales. Estudios Mujer y violencia, 1-16. http://bdigital.unal.edu.co/39968/1/Mujer\%20y\%20violencia.pdf [Consultado el 19 de agosto de 2019].

Meertens, D. (2000). Ensayos sobre la tierra, violencia y género: hombres y mujeres en la historia de Colombia. Universidad Nacional de Colombia. https://epdf. pub/ensayos-sobre-tierra-violencia-y-genero.html [Consultado el 19 de agosto de 2019].

Meertens, D. (2016). Entre el despojo y la restitución: reflexiones sobre género, justicia y retorno en la costa caribe de Colombia. Revista Colombiana de Antropología, 45-71. http://www.scielo.org.co/pdf/rcan/v52n2/04866525-rcan-52-02-00045.pdf [Consultado el 20 de agosto de 2019].

Mesa de Conversaciones (2016). Acuerdo final para la terminación del conflicto: hacia la construcción de una paz estable y duradera. http://www.altocomisionadoparalapaz.gov.co/herramientas/Documents/Acuerdo-Final-AF-web. pdf [Consultado el 19 de agosto de 2019].

Ministerio de Salud y Protección Social (2016). La mujer rural en Colombia. https://www.minsalud.gov.co/sites/rid/Lists/BibliotecaDigital/RIDE/ VS/PP/SNA/Boletin-O2-20 15-Mujer-Rural\%2O-agricultura-familiar-Colombia.pdf [Consultado el 15 de septiembre de 2018 ].

Ostrom, E. (2002). El gobierno de los comunes. La evolución de las instituciones de acción colectiva. México, D. F.: FCE.

Parada, M. (2018). Entre el avance y las barreras. Enfoques de igualdad de género en la política pública en Colombia. Estudios Socio jurídicos, 20(2), 103128. https://revistas.urosario.edu.co/index.php/sociojuridicos/article/ view/6612 [Consultado el 10 de octubre de 2018].

Puigvert, L.; Muñoz, B. (2012). Gender Studies. Barriers and Contributions to the Theoretical International Debate from the voices of the Other Women. Géneros, 1(1), 1-25. http://hipatiapress.com/hpjournals/index.php/ generos/article/view/172/201 [Consultado el 20 de octubre de 2018 ].

Revilla, M. (2010). América Latina y los movimientos sociales en la presente rebelión del coro. Nueva sociedad, 227, 52-67. https://nuso.org/media/articles/downloads/3696_1.pdf [Consultado el 13 de septiembre de 2018]. 
Revista Semana (Agosto 15, 2015). Una dura radiografía del campo colombiano. https://www.semana.com/economia/articulo/campo-colombiano-en-la-pobreza/438618-3 [Consultado el 19 de abril de 2019].

Robinson, J. (2016). La miseria en Colombia. Desarrollo y Sociedad-Universidad de los Andes, 76, 9-88. www.redalyc.org/pdf/1691/169144237001.pdf [Consultado el 18 de septiembre de 2018].

Rueda, M. (2016). Globalización y sistemas socio-ecológicos tropicales: efectos diferenciados del café sobre los productores y ecosistemas locales en el trópico andino colombiano. En J. C. Young. Naturaleza y Sociedad: perspectivas socio ecológicas sobre cambios globales en América Latina (pp. 411-452). Lima, Perú: Instituto de Estudios Peruanos.

Santos, J. M.; Jiménez, T. (2016). Acuerdo final para l terminación del conflicto. http://www.altocomisionadoparalapaz.gov.co/procesos-y-conversaciones/Documentos\%20compartidos/24-11-2016NuevoAcuerdoFinal. pdf [Consultado el 15 de mayo de 2018].

Secretaría Distrital de la Mujer (2017). 6.000 mujeres protagonistas del proceso de restitución. https://www.funcionpublica.gov.co/-/mujeres-victimas-delpais-se-empoderan-en-procesos-de-restitucion-de-tierras [Consultado el 14 de septiembre de 2918].

Shön, D. (1992). La formación de profesionales reflexivos. http://csmvigo.com/pedagoxia/files/2016/07/D.A.-SCH\%C3\%96N-LA-FORMACI\%C3\%93NDE-PROFESIONALES-REFLEXIVOS.pdf [Consultado el 14 de septiembre de 2018].

Soto, P.; Fawaz, M. (2016). Ser mujer microempresaria en el medio rural. Cuadernos de desarrollo rural, 13(77), 141-167. http://www.scielo.org.co/pdf/ cudr/v13n77/0122-1450-cudr-13-77-00141.pdf [Consultado el 24 de octubre de 2018].

Stromquist, N. (2015). Women's Empowerment and Education: linking knowledge to transformative action. European Journal of Education, 50, 1-16. https://onlinelibrary.wiley.com/doi/pdf/10.1111/ejed.12137 [Consultado el 24 de octubre de 2018]. 
Unidad de Restitución de Tierras (2019). Estadística de restitución. https://www. restituciondetierras.gov.co/estadisticas-de-restitucion-de-tierras [Consultado el 17 de agosto de 2019].

Unidad para la Atención Integral a Víctimas (2019). Cifras de víctimas en Colombia. https://cifras.unidadvictimas.gov.co/Home/Genero?vvg=1 [Consultado el 13 de Septiembre de 2018].

Uribe, M. (2012). Estilos de desarollo y sesgo anticampesino en Colombia. Cuadernos de Economía, 32(60), 505-535. https://revistas.unal.edu.co/index. $\mathrm{php} /$ ceconomia/article/view/40122/42280 [Consultado el 12 de septiembre de 2018].

Vargas, G.; Hurtado, R. (2017). Documentos de Política, los retos de la paz territorial. Bogotá, Colombia: Universidad de los Andes.

Vargas, M. (Enero, sábado 1, 2018). En los últimos 7 años se ha dado un impulso al campo. El Tiempo.com. https://www.eltiempo.com/economia/sectores/ crecimiento-del-campo-colombiano-en-los-ultimos-siete-anos-243644 [Consultado el 12 de septiembre de 2018].

Viera, M. (2012). Mirarse y ser vistas. Objetivación de dos colectivos de mujeres rurales. Adamios: revista de investigación social, 9(19), 337-358. http://www. scielo.org.mx/pdf/anda/v9n19/v9n19a15.pdf [Consultado el 22 de octubre de 2018].

Zuluaga, G. P.; Arango, C. (2013). Mujeres campesinas: resistencia, organización y agroecología en medio del conflicto armado. Cuadernos de desarrollo rural, 1O(72), 159-180. http://www.scielo.org.co/pdf/cudr/v10n72/v10n72a09. pdf [Consultado el 25 de 10 de 2018]. 